\title{
DESIGN AND DEVELOPMENT OF MACHINE FAULT SIMULATOR (MFS) FOR FAULT DIAGNOSIS
}

\author{
Chitresh Nayak ${ }^{1}$,Vimal Kumar Pathak ${ }^{2}$, Sagar Kumar ${ }^{3}$. Prashant Athnekar ${ }^{4}$ \\ 1,2,3,4 Department of Mechanical Engineering, MNIT, Jaipur
}

\begin{abstract}
Recent years have seen the rise of vibration problems associated with structures, which are more delicate and intricate, machines that are faster, more complex and production process that are automated and interlinked. The occurred problems are directly related to demands of lower investment, running and maintenance cost in incidence with the requirement of increase productivity and efficiency. This work developed aMachine Fault Simulator (MFS), whichis the most comprehensive laboratory scale machine on the market for performing rotor dynamics experiments.Also, it helps in learning vibration signature of the most common machinery faults in a controlled manner without compromising your quality production/ profits. The bench top system has a spacious modular design featuring versatility, operational simplicity and robustness in depth studies of a variety of faults can be conducted using over many applications. Some examples are rolling element bearing defects, Gear defect, belt and pulley defect, motor bearing defect.
\end{abstract}

\section{KEYWORDS}

Machine Fault Simulator, vibration analysis, rotating elements, fault diagnosis.

\section{INTRODUCTION}

Machinery fault diagnosis is finding a specific fault or failure that are produced in a system. Condition based maintenance can significantly cut routine maintenance costs. Machinery condition monitoring Covers distinctive disciplines such as mechanical measurements, electrical measurements, performance and process measurement and tribology. Fault detection and diagnosis can be broadly classified into two categories, i.e. Fault generator and Vibration analysers. Fault generator is the Machine Fault Simulator (MFS) unit. MFS comprises of a shaft rotor assembly driven by an AC motor.

MFS comprises facilities to introduce various machine faults like faulty bearings, damaged gear and faulty belt drive [1]. Vibration Analyser hardware was used for vibration signal acquisition \& processing. The signal acquired was further processed in signal analysis software [2].The early detection of faults can help avoid system shutdown, breakdown and even catastrophes involving human fatalities and material damage. A systemthat includes the capacity of detecting, isolating, identifying or classifying faults is called a fault diagnosis system [3]. The common types of machine faultsareUnbalancing, Damaged or loose bearings, damaged gears, Faulty of misaligned belt drive, mechanical looseness, increased turbulence and electrical induced vibration.

Fault detection using vibration analysis involves analysing the vibration signature for signs of fault. Any predominant fault occurring results in increased vibration level, which has energy concentrated at certain frequency levels. The faultis not only based on the structure's operating 
environment, but also the type of monitoring system that is used [4, 5]. The common types of gear damage mainly consist of pitting, scuffing, spalling, cracking and wear. One of the major reasons for gear fault is excessive vibration [6]. Extensive literature is available on diagnosing rolling element bearing defects using vibration analysis. Such as the effects of speed and damage severity on the vibration signature. Authors have discussed different techniques for Machine fault signature analysis of rotating elements [7]. Few author discussed gear fault feature based on dominant intrinsic mode function [8].Machinery Fault Simulator (MFS) provides a platform to study bearing faults. The following tests are performed on GYE25KRRB bearings with lightly and moderately faulted outer race. The above literature presented provides an idea about the development of MFS and their fault diagnosis techniques. The earlier MFS developed were costly and complex in design. Also, the fault diagnosis was performed only for a few elements.

In the present work, the belt drive is not connected to prevent interference in the spectrum. The faulted bearing is installed in the inboard bearing housing. Accelerometers are installed in vertical and horizontal directions on the motor and two bearing housings. This work design and developsan MFS for rotating elements to identify fault diagnosis and vibration analysis. The basics and underlying physics of vibration signals are first examined. The latest approaches and equipment used together with current research techniques in vibration analysis are also highlighted in the paper. The Machine fault simulator developed is a low-cost set-up and simple in design. Additionally, fault diagnosis can be performed for all rotating elements.

\section{MACHINE FAULT SIMULATOR (MFS)}

The simulator is designed, so that it is both easy to operate and versatile. The instrument is constructed with special kinds of bearings, a split bracket bearing housing, multi-purpose belt tensioning and gear mounting mechanism, and reciprocating system, all of which make it easy to remove and replace various components for specific types of tests. Here are just a few of the design features that make the Machinery Fault Simulator easy to use without sacrificing the performance you need. The test rig consists of a three-shaft with agear on thefirst and second shaft and two overhang pulleys on thesecond shaft and athird shaft, which is supported on the bearings.

\subsection{Proposed Methodology}

This study is initialized as a first step towards evolving a model based diagnostic system for rotating elements that will make full use of the information in the vibration data being collected. The methodology for the MFS is based on characteristics of various types of vibration encountered in rotating machinery. The framework for proposed methodologyis shown in Figure1.

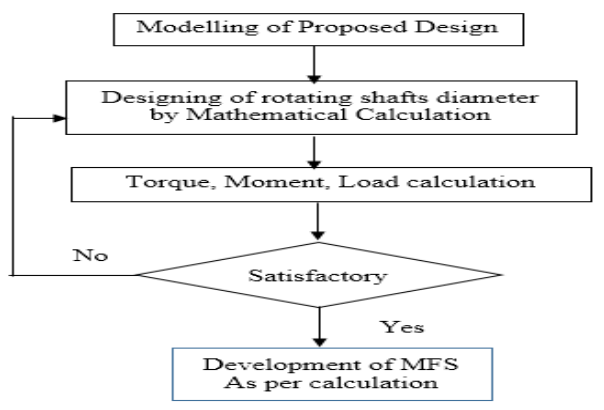

Figure 1. Proposed Methodology 


\subsection{Experimental Rig Design}

An MFS has been designed and fabricated in order to demonstrate some of the most commonly found faults in rotating machinery. The following faults can be illustrated using MFS: misalignment (parallel and angular), imbalance, mechanical looseness, bent shaft, bearing fault, gear fault, eccentric pulley, electric motor fault, vane passing frequency and missing blade.An experimental test rig built to predict defects in GYE25KRRB bearing is shown in Table 1. The test rig consists of a three-shaft with agear on thefirst and second shaft and two overhang pulleys on second shaft and third shaft, which is supported on the bearings [9, 10]. The Experimental setup for Vibration Based Fault Diagnosis of Rolling Element Bearings can be broadly classified into two categories:FaultGenerator and Vibration analyzers. Fault Generator is the Machine Fault Simulator (MFS) unit.

Machine Fault Simulator comprises of a shaft gear assembly driven by an AC Motor. Machine Fault Simulator comprises facilities to introduce various machine faults like misalignment, faulty bearings, damaged gear and faulty belt drive. The details of the bearing used in the present are given in Table 1. FFT analyzer CSI 2400 Dynamic Vibration analyzer was used to monitor vibration signals from good and defective bearings. The design of the machine fault simulator is prepared by using Creo Parametric 2.0 and final isometric, and wireframe view is shown in Figure 2.

Table 1. Roller Bearing Details [GYE25KRRB]

\begin{tabular}{|c|c|c|}
\hline S No & Parameter & Value \\
\hline 1 & Number of rollers & 10 \\
\hline 2 & Outer diameter [mm] & 52 \\
\hline 3 & Inner diameter [mm] & 25 \\
\hline 4 & Pitch Diameter [mm] & 39 \\
\hline 5 & Roller diameter $[\mathrm{mm}]$ & 8 \\
\hline
\end{tabular}
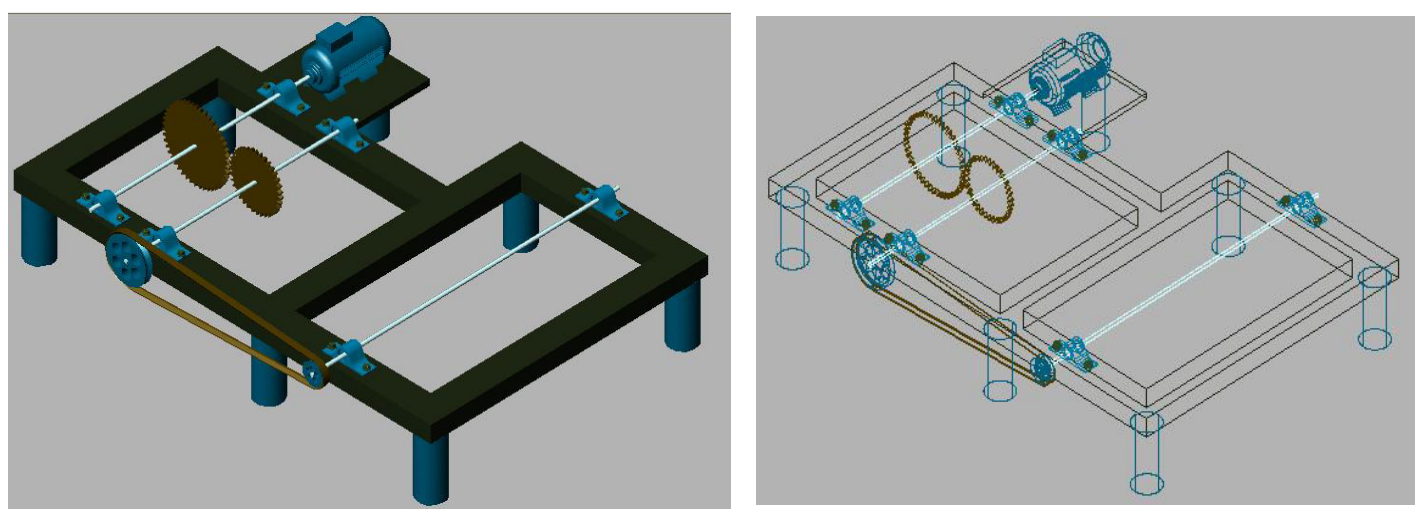

Figure 2. Isometric and wire frame view of machine fault simulator

Engineering structures and systems are designed to operate within limits specified by the environment in which they will be used. At the design stage, the loading of the structure is defined, and appropriate material choices are made based on their properties. In many cases, prototypes are built, and stringent experimental testing is carried out. Increasingly, engineers rely on modelling techniques to obtain knowledge of the structure'sbehavior in the operating environment. The constructional parts of MFS are precision machined to high tolerances. It has 
a modular and flexible design for easy upgrades and installation. Use of rigid, slippage-free operation using typical components from manufacturing. MFS includes removing and replacing parts are couplings, bearings, shaft, pulleys, motor and belt can be changed without removing bearing housing $[11,12]$.

\subsection{Designing of Rotating Shaft}

It is the rotating part of the rotor-bearing system. It consists of a solid steel shaft of diameter 28 $\mathrm{mm}$ and length $650 \mathrm{~mm}$ were used. A flexible coupling connects the rotor to the motor driver shaft. Shafts with a heavy pre-load carried by the bearings, as distinct from the out-of-balance load, can show variation characteristics similar to those caused by bearing misalignment. For understanding behavior of shaft, variable load, equivalent stress, shaft based stiffness, torsional rigidity and critical speed of shaft are considered. The mathematical calculation for the designing of shaft 1 and shaft 2 are given below.

Let us take $45 \mathrm{c} 8$ steel and using electric motor having

\begin{tabular}{|c|c|}
\hline $\begin{array}{l}\text { Power } 1 \mathrm{H} . \mathrm{P}=.75 \mathrm{KW} \\
\text { Power }(\mathrm{P})=.75 \mathrm{~kW}=750 \mathrm{~W} \\
\text { Number of revolution per minute }=1440 \mathrm{rpm} \\
\text { Pressure angle }(\phi) 20^{\circ} \\
\text { For } 45 \mathrm{c} 8 \text { steel }(\text { from design data Book) } \\
\text { Ultimate tensile strength } 610-700 \mathrm{Mpa}=\sigma_{\mathrm{ut}} \\
\text { Take factor of safety }=6 \\
\sigma_{\mathrm{b}} \text { or } \sigma_{\mathrm{t}}=690 / 6=115 \mathrm{Mpa} \\
\tau_{\mathrm{u}}=0.75, \sigma_{\mathrm{ut}}=0.75 \times 690=517.5 \mathrm{Mpa} \\
\tau_{\mathrm{s}}=\tau_{\mathrm{u}} / 6=86 \mathrm{Mpa} \\
\text { DESIGN DIAMETER FOR SHAFT } 1 \\
\text { Torque, } \mathrm{T}=\mathrm{P} \times 60 / 2 \pi \mathrm{N}=750 \times 60 / 2 \pi \times 1440 \\
=\underline{4.9736 \mathrm{Nm}} \\
\text { Tensile force, } \mathrm{F}_{\mathrm{t}}=2 \mathrm{~T} / \mathrm{D}=2 \times 4.9736 / 210 \times 10^{-3} \\
=\underline{47.3676 \mathrm{~N}} \\
\text { Resultant force, } \quad \mathrm{F}_{\mathrm{R}} \quad=\quad \mathrm{F}_{\mathrm{t}} \times \quad \text { tan } \phi \\
47.3676 \times t a n 20 \\
=17.2404 \mathrm{~N} \\
\text { Total horizontal Load } \mathrm{F}_{\mathrm{t}}=47.3676 \mathrm{~N}(\rightarrow) \\
\text { Total vertical Load }=\mathrm{F}_{\mathrm{R}}+\mathrm{W}=17.2404+50 \\
\mathrm{~d}=8.81 \mathrm{~mm} \\
\text { Therefore, the nearest standard diameter of } \\
\text { the shaft being selected at } 28 \mathrm{~mm} . \\
\text { DESIGN DIAMETER FOR SHAFT } 2 \\
\text { Torque } \mathrm{P} \times 60 / 2 \pi \mathrm{N}=750 \times 602 \pi \times 1938 \\
=\underline{36.955 \mathrm{Nm}} \\
\text { Tangential on gear at } \mathrm{C} \\
\mathrm{F}_{\mathrm{t}}=2 \mathrm{~T} / \mathrm{D}=2 \times 36.955 / 156 \times 10^{-3} \\
=\underline{473.788 \mathrm{~N}} \\
\text { Load }=\mathrm{Normal} \text { Load acting on gear } \\
\mathrm{W}=\mathrm{F}_{\mathrm{t}} / \text { cos } \phi=504.194 \mathrm{~N} \\
\text { Horizontal component of load } \mathrm{W}\end{array}$ & 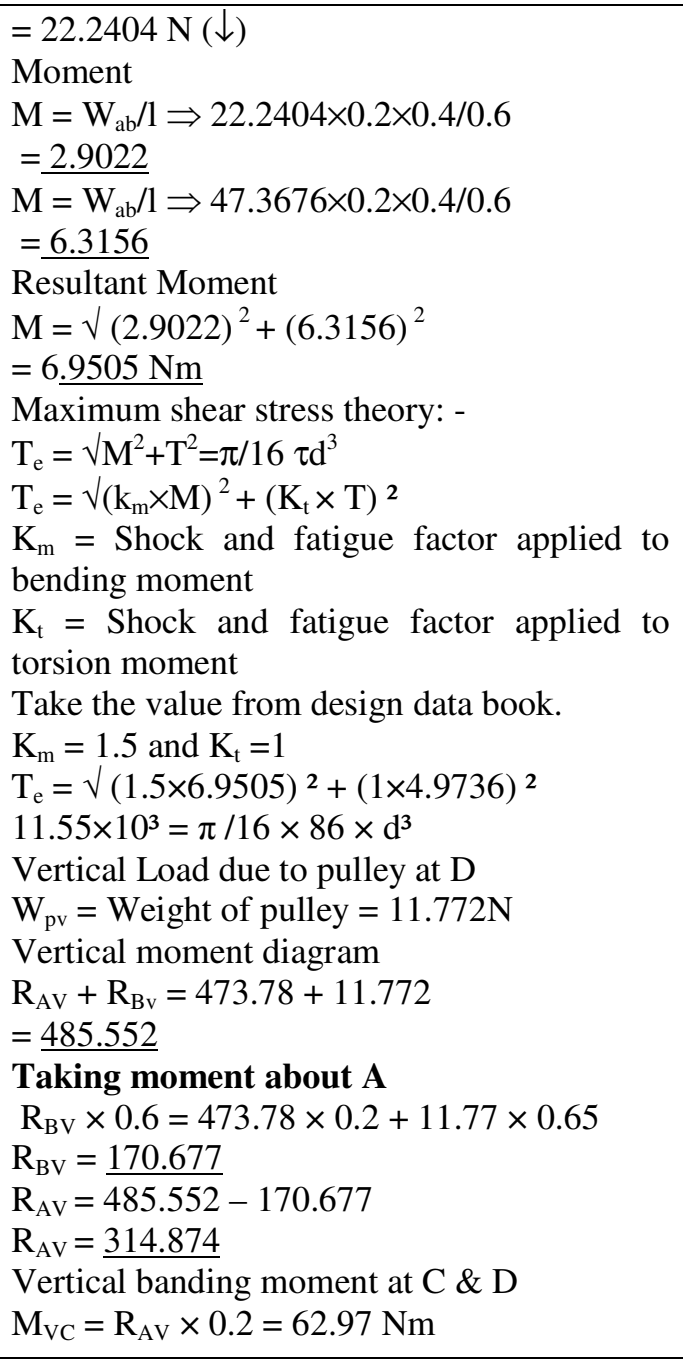 \\
\hline
\end{tabular}


International Journal of Recent advances in Mechanical Engineering (IJMECH) Vol.4, No.4, November 2015

\begin{tabular}{|c|c|}
\hline 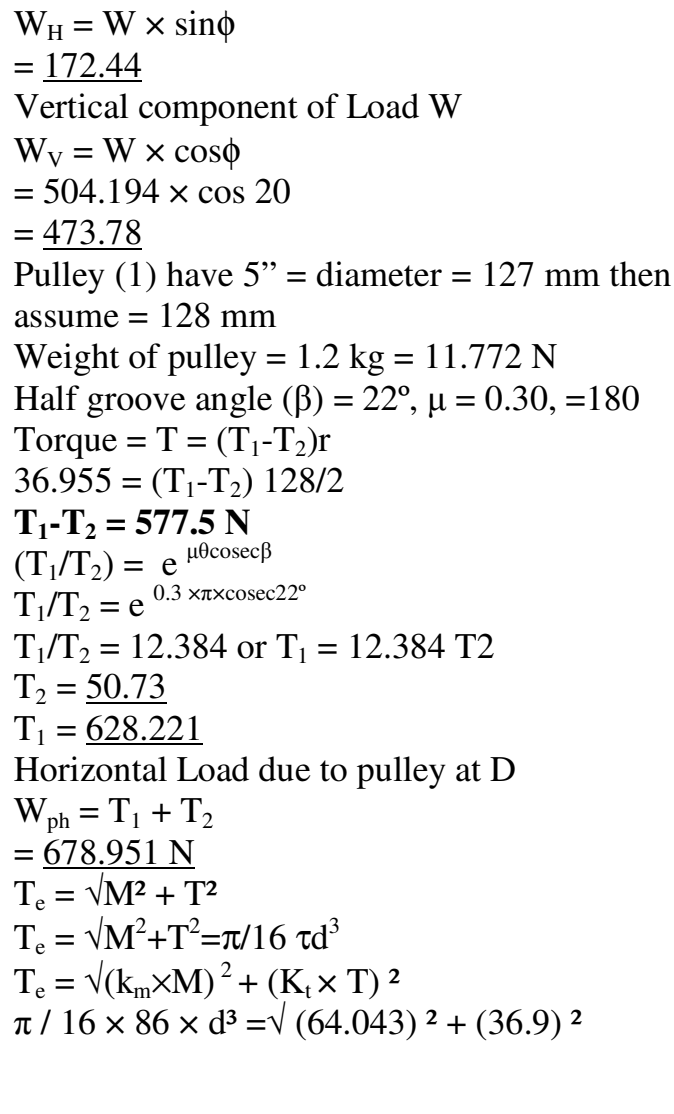 & 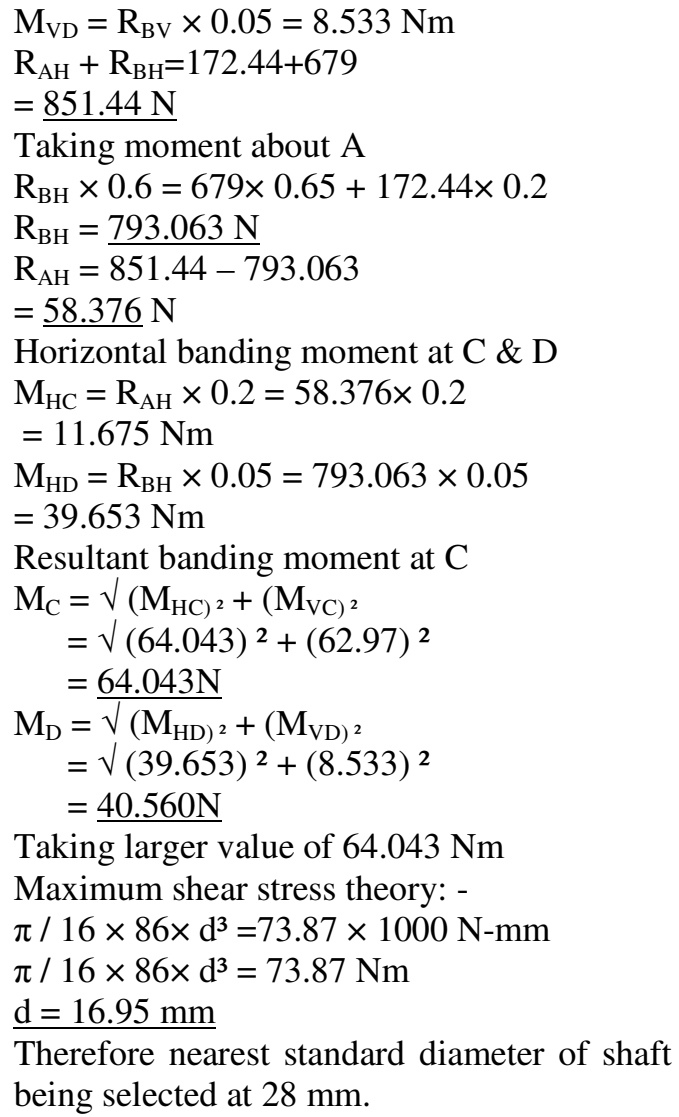 \\
\hline
\end{tabular}

\section{RESULTS}

The machine fault simulator developed (see Figure 3) in this work is capable of accurate analysis, thefault of machine element and its causes. Machine fault simulators can diagnosis regarding vibration, noise, wear, lubrication.Helical gear was usedfor the purpose of high strength and low noise. Easy to install gears of different sizes/types, and to introduce a variety of faults for controlled studies.

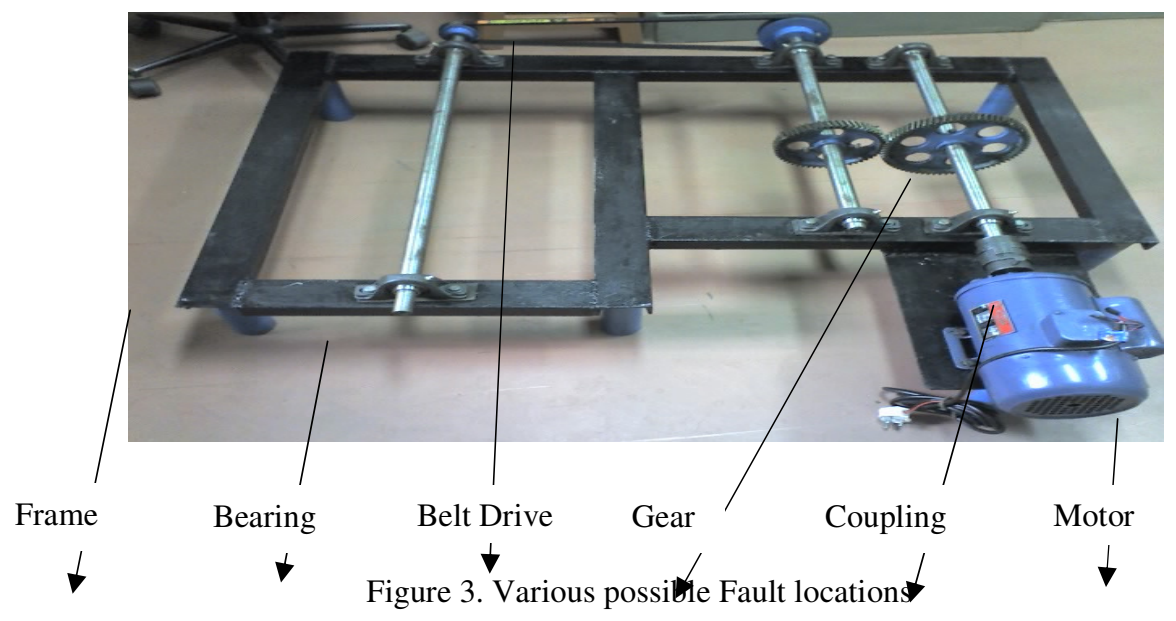


International Journal of Recent advances in Mechanical Engineering (IJMECH) Vol.4, No.4, November 2015

Maintenance of machine can be carried out very fast in regarded to thediagnosis of the problem thatreduces investment cost of machine, ideal time of plant, reduce non-productive man hours. Hence, it also increases productivity, quality, effectiveness, efficiency, consistency of the product. Torque, vertical-horizontal load, vertical-horizontal and resultant bending moment test were performed on the shaft. The results for above tests were shown below in Figure 4. A and B are bearing, C is helical gear and D is acoupling of the developed MFS as depicted in Figure. During testing of proposed system, it was observed that with rotation of the motor at 1440 RPM,vertical load on gear $\mathrm{C}$ is $473.78 \mathrm{~N}(\downarrow)$ and horizontal load is $172.44 \mathrm{~N}$ in a downward direction. The vertical load on coupling $11.772 \mathrm{~N}(\downarrow)$ and thehorizontal load is $678.95 \mathrm{~N}(\downarrow)$. A resultant bending moment on gear and coupling are $64.04 \mathrm{Nm}$ and $40.50 \mathrm{Nm}$ respectively. The results shown are by the standards defined.

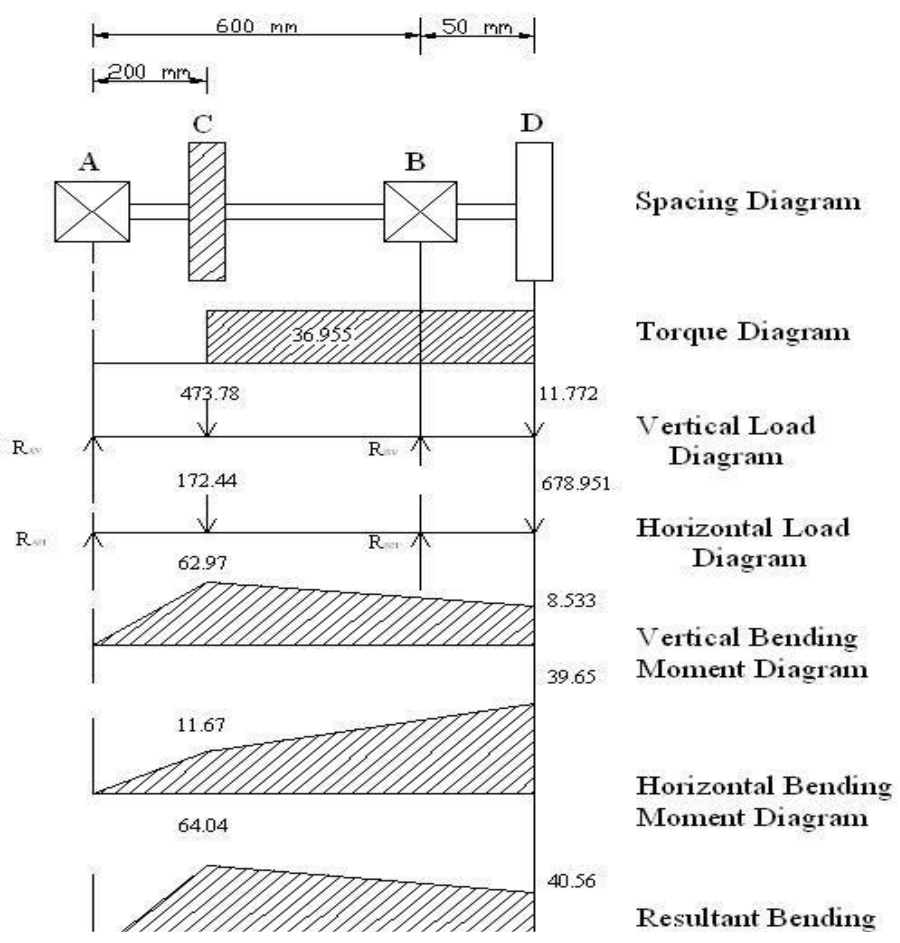

Figure 4. Line diagram of Torque, Load and Moment for MF

\section{CONCLUSION}

The Machine Fault Simulator is an essential tool for analysis, development for vibration.An investigation into factor affecting the development of a Machine Fault Simulator for fault diagnosis in bearing machine fault are affected by vibration, noise, wears, lubrication, moisture, and dust. Studies can be performed on the vibration spectra of common faults, learn fault signatures, vibration based diagnostic techniques, lubricant condition and wear particle analysis.

The parameter should be maintained for better performance of the system. A Gear diagnostic and prognostic method was developed. This system highlights the discrepancy in gear diagnosis and prognosis due to many hidden factors beyond just the operating condition. The methodology can be extended to other gear where geometries of gear and materials are different.Different speeds of three shafts allow demonstration of frequency analysis methods. 
International Journal of Recent advances in Mechanical Engineering (IJMECH) Vol.4, No.4, November 2015

The future scope includes study the temperature pattern and find out the best location to put temperature sensor or any other way to get maximum available temperature. Find out the best location and the environment to sense the fault signature sound. To enclose the gear within the gearbox within the gearbox filled with oil, one gear is made by brass and another gear is made of cast iron that could be used for wear test through oil analysis. Designed in parallel shaft gearbox can be configured as single/double stage reduction/increase. Easy to install gears of different sizes/types, and to introduce a variety of faults for controlled studies. We can assemble rotors with split collar ends for easy replacement and installation of the shaft that is connectedto coupling motor. The helical gear is made of brass because of reduce noise and vibration.Additional devices may be mounted on the output shaft.

\section{REFERENCES}

[1] J. R.Stack, T. G.halter\&R. G.Harley, (2003) "Fault Classification and Fault Signature Production for Rolling Element Bearings in Electric Machines", Diagnostics for Electric Machines, Power Electronics and Drives, SDEMPED 2003. 4th IEEE International Symposium, 172-176.

[2] Y. H. Kim, B.D. Lim, and W.S. Cheoung. (1991) "Fault Detection in a Ball Bearing System Using a Moving Window",Mechanical Systems and Signal Processing, 5(6), 461-473..

[3] P. W. Tse, W. Yang, and H. Y. Tam. (2004) Machine fault diagnosis through an effective exact wavelet analysis. Journal of Sound and Vibration, 277:1005-1024.

[4] G. Dalpiaz, G. DElia, and S. Delvecchio. (2007) Design of a test bench for the vibroacoustical analysis and diagnostics of rotating machines. In WCEAM-CM2007, Harrogate, United Kingdom.

[5] V. Sugumaran, G.R. Sabareesh, K. I. Ramachandran, (2006) “ Fault Diagnosis Of A Taper Roller Bearing through Histogram Features And Proximal Support Vector Machines”, International Conference on Signal and Image Processing.

[6] Z. K. Zhu, Z. H. Feng, and F. R. Kong. (2005) Cyclostationarity analysis for gearbox condition monitoring: Approaches and effectiveness. Mechanical Systems and Signal Processing, 19:467-482.

[7] P Jayaswal, A K Wadhwani, K B Moolchandani, (2008) "Machine Fault signature analysis", International Journal of Rotating Machinery, Hindawi Publishing corporation.

[8] ZhifengLiu,Bing Luo, Wentong Yang, LigangCai, Jingying Zhang, (2014) "Approach to extracting gear fault feature based on dominant intrinsic mode function", Proceedings of the Institution of Mechanical Engineers, Part C: Journal of Mechanical Engineering Science.

[9] J. R. Stack, ThomasG.habelter and Ronald G.harley, (2003) "Effects of Machine Speed on the Development and Detection of Rolling Element Bearing Faults", IEEE power electronics letters.

[10] W. Y. Wang, and MJ Harrap, (1996), Condition Monitoring of Ball Bearings Using Envelope Autocorrelation, Technique Machine Vibration, 5, 34-44

[11] C. J. Verucchi, G. G Acosta \& FA Benger, (2008) "A review on fault diagnosis of induction machines," Latin Amer. Appl. Res., Vol. 8, No. 2, pp. 113-121.

[12] Spectra Quest, Inc., "Machinery Fault Simulator", http://spectraquest.com/machinery-faultsimulator/details /mfs/, 2012.

\section{Authors}

Mr. ChitreshNayak is Research scholar in Mechanical Engineering at Malaviya National Institute of Technology Jaipur (Rajasthan, India). He did his graduation at RGPV University Bhopal and M.Tech at MITS Gwalior both in MechanicalEngineering. His research interests include Reverse Engineering and rapid prototyping. He has about 10 journal and conference publications in his credit.




Mr. Vimal Kumar Pathak is Ph.D. research scholar in Department of Mechanical Engineering at Malaviya National Institute of Technology, Jaipur, India. He has done his masters from ISM Dhanbad (now IIT Dhanbad) in Maintenance Engineering and Tribology. His area of interests are advanced tribology, Reverse Engineering, Rapid Prototyping, Automatic inspection, Optimization, Geometric Dimensioning and Tolerancing.

Mr. Sagar Kumar is Ph.D. research scholar in Department of Mechanical Engineering at Malaviya National Institute of Technology, Jaipur. He has done his Masters from VNIT, Nagpur in CAD/CAM. His area of Interests are Tribology, Rapid Tooling, Reverse Engineering and $\mathrm{CAD} / \mathrm{CAM} / \mathrm{CAE}$.

Mr. Prashant Athnekar is Ph.D. research scholar in Department of Mechanical Engineering at Malaviya National Institute of Technology, Jaipur. He has done his Masters from SGSITS Indore in Computer Integrated Manufacturing. His area of Interests are Tool Design and Development, Rapid Tooling, Reverse Engineering and Mold Design.
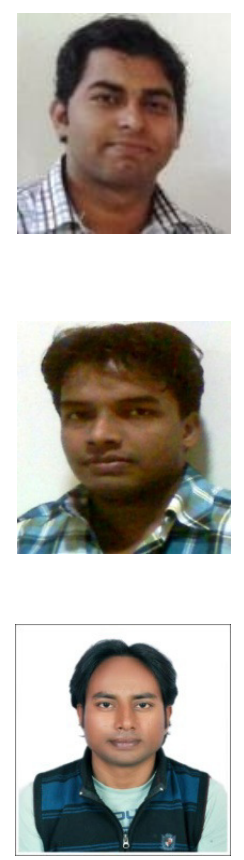